\title{
Macroeconomic indices and capital market: evidence from Tehran Stock Market
}

\author{
Seyed Nezamuddin Makiyan
}

Associate Professor, Department of Economics, University of Yazd, Iran

\section{Hamid Alibeiki}

Professional Lecturer, Department of Economics, Imam Javad University, Iran

\begin{abstract}
The increasing trend of financial market makes it necessary to study about these markets. Stock market is one of the basic components of the financial markets. Besides equipping local savings and leading them to production, stock market as an important part of the capital market is able to support growth and expansion of the economy. Stock market not only impacts the national economy, but also it influences on the international economy as well. Therefore, there is a significant relation between the evolution of stock market and economic boom and depression, and also macroeconomic variables in each country. In view of the fact that stock market index is affected by different factors, especially macroeconomic variables, this research aims to investigate the effect of such variables (inflation, liquidity, real exchange rate) on the stock price index of the Tehran Stock Exchange using monthly data and considering Auto-Regressive Distribution Lag Method (ARDL) during the period of 2005-2014. The results of the research show that there is a long run relation between stock price index and the investigated variables (inflation, liquidity and real exchange rate). According to the findings, inflation due to current public spending and revising portfolio has a negative effect on the Tehran Stock Price index. In addition, real exchange rate and inflation has a negative effect on such an index.
\end{abstract}

Keywords: inflation, liquidity, real exchange rate, Tehran Stock Price index, ARDL method.

JEL Classification: C5, G1, E44.

DOI: $10.21272 / \mathrm{sec} .1(2) .19-26.2017$.

(C) The Authors, 2017. This article is published with open access at ARMG Publishing.

\section{Introduction}

By introducing the private sectors in the economic activities and the increasing participation of this section in the economy, the revitalization of the stock exchange has been considered. The governments seek to implement the privatization policy, attract the funds and the investors into the productive and economic activities by which they could provide the priorities of the economic growth. The Tehran Stock Exchange started a new period from 1980 in order to increase the interests of the public to the investment and moving the stagnant funds to the productive economic activities for supplying the financial needs of the manufacture entities. Due to the economic situation after Iran's war and the effects of the changes in the macroeconomic variables including inflation, liquidity and exchange rate on the stock market indices, the exchange market observed much volatility. The extensive numbers of the effective factors of capital market made it uncertain to make investments in this market. Clearly, uncertainty seems to be a dissatisfactory element in investment. The fact that the economic variables such as inflation, liquidity and exchange rate are influential in the stock price changes is widely accepted. Since these economic variables have been problematic and the investment in the financial markets is risky, it seems necessary to examine these variables in the Iranian economy. Using Auto-Regressive Distribution Lag Method (ARDL), the magnitude of the effects of this factor has been examined. Based on the economic theory, the inflation and real exchange rate are expected to be negatively associated with the total stock price index. However, a positive relationship is expected between liquidity and total stock price index. After having a description of the research background, the theoretical bases are developed and the model is described. Finally, the conclusions are provided and the results are interpreted.

\section{Theoretical dases}

Stock price index is the first and significant factor for making investment decisions in the stock exchanges. In doing so, it seems necessary to become aware of the effective factors of the stock price. Based on Fisher (1930), the effective factors of the stock price index are categorized into two general classes: 
1. Internal factors: These factors include the effective factors associated with the firm's operations and the decisions.

2. External factors (Macro-factors): These factors include those effective factors which are out of control of the managers and affect the firm's operations. These factors might be studied in terms of two groups of political and economic factors. Furthermore, the economic factors might be examined in terms of two groups including real and monetary variables (Karim Zadeh, 2006). Inflation, liquidity and real exchange rate are among the important external factors having been examined in this study.

\subsection{Inflation and stock price index}

Over the inflation period, the nominal earnings of the firms increase after a long term. In fact, the profitability does not increase but the nominal earnings increase by inflation. When the nominal earnings increase, the nominal stock price also increases. The other effect of inflation is that it will cause the reduction in the intrinsic value per share. In those years with high inflation rates, the quality of the real earnings (economic earnings) reduces. In addition, the inflation situation reduces the purchase power of the people. Increases in the life expenses have taken the investment and savings opportunity and caused the revenues to be spent over the current costs. Fewer investments result in lower demand of the investors in the stock exchanges and also lower returns and stock index (Sajjadi et al., 2010). As a consequence, the profitability of some industries temporarily increases and it can be concluded that there is a positive relationship between the changes in inflation and the stock price index in short term. However, these variables are expected to be negatively associated in the long-term because the manufacturing costs and the expected return rates of the investors are increased.

\subsection{Liquidity and stock price index}

Based on the monetary theories of inflation, the necessary and enough condition for the continuous inflation occurs when the liquidity increases by a rate higher than the multiply of real revenue growth rate and revenue elasticity of demand (Laidler and Parkin, 1975). Increasing liquidity might increase the demand for making investments including the demand for the stocks. As a result, there should be a positive relationship between liquidity and stock price index. Due to the lack of sufficient infrastructures for attracting investments in the manufacturing sectors of the developing countries, the liquidity is spent over the spectacular activities. Therefore, the increases in the liquidity will not be accompanied by increases in the gross national production and might be a factor for intensifying inflation. Consequently, no strict opinion is expressed for the way the liquidity impacts the stock index.

\subsection{Exchange rate and stock price index}

The exchange rate plays an essential role in economic regimes including non-developed countries. Most of these countries are dependent upon the industrialized countries for their economic development. Most of the manufacturing enterprises intend to import the raw materials, technologies and machinery. By increasing the exchange rate, the costs of the products, the gross margin and earnings per share also increase. In doing so, the stock price decreases and the total stock index changes (Imran et al., 2010). Given the dependency of the listed firms to the import, it is expected that the companies lose their competitiveness by increases in the exchange rate. Therefore, the main hypothesis of this study states that there is a negative relationship between increases in the exchange rate and the total stock price index of the Tehran Stock Exchange.

\section{Literature review}

Keung-Wing, Khan and Du (2006) examined the relationship between the stock price index and the macroeconomic variables including the supply of money and interest rate in Singapore and United States of America over a period from 1982 to 2002. Using the model of Johanson and Grenjery, they found that the stock index of Singapore has a long-term balancing relationship with the interest rate and money volume. However, this relationship was not found in the United States.

Salifu et al. (2007) investigated the effect of changes in the exchange rate on the stock market of Ghana. Their findings revealed that 55 percent of the examined firms have been affected by the changes in the dollar price of the United States. The effect of changes in the dollar price of the manufacturing industries and retailers is stronger; however, the financial industry is not affected by the changes in the dollar price. The stock returns of most of the firms are found to be directly associated with the changes in the dollar rate. 
Adaramola et al. (2010) examined the impact of six macro-economic variables on the stock price index of the selected listed firms on the Nigerian Stock Exchange. The selected macro-economic variables include interest rate, oil price, exchange rate, money supply and gross domestic production. The research data include season data for a period from 1985 to 2009 and 36 firms finally selected. The estimations of this study have been made based on GLS method. The findings revealed that the exchange rate and interest rate are negatively associated; however, the oil price and gross domestic products were found to be positively associated with the stock price index. The two variables of inflation rate and money supply were found to be insignificant. The results also confirm that the Nigeria Stock Exchange is strongly affected by the three variables of interest rate, exchange rate and oil price.

Komar Naik and Padhi (2010) employed VECM method to examine the long-term relationship between the exchange index of Bombay and five macro-economic variables including industrial manufacturing index, wholesale price, money supply, interest rate and treasury rate. The collected data were in monthly form and covered 18 years from 1994 to 2011. They concluded that there is a long-term relationship between these variables and the stock price index is positively associated with the money supply and the index of the industrialized manufactures. However, it was found that this relationship is negative for the wholesale price and treasury rate. Finally, the interest rate was found to be statistically insignificant.

Among notable studies, we can accentuate on some new literature in this scope in Iran:

Najjar Zadeh et al. (2009) evaluated the impact of interest rate and inflation rate on the stock price index of Iran. The model has been analyzed by vector autoregressive, impulse response function and variance analysis. The required data was gathered monthly over 2003 to 2006 . The authors found that the impacts of the exchange rate volatilities and the price changes in the short-term and mid-term will cause an increase in the stock price and will result in a decrease in the stock price of the Tehran Stock Exchange in the long term.

Mousayi et al. (2010) examined the association of the stock price index and the variables including money supply, interest rate and gross domestic production by using ARDL method. The data was gathered quarterly over 1991 to 2006. The findings revealed that the constant monetary policy plays significant roles in mitigating the uncertainty of the stock market. The relationship between the stock price index and money supply and gross domestic product was estimated to be positive; however, this relationship was estimated to be negative for the exchange rate and this is consistent with the economic theories. The changes in the money volume have the highest effect on the stock price index. Furthermore, ECM coefficient (showing the modification of the stock price from short-term to the long-term) was estimated to be $16 \%$.

Taheri et al. (2011) examined the long-term relationship between the exchange rate and the stock price index on the Tehran Stock Exchange. The data was gathered monthly over 2002 to 2008 by using ARDL method. The stock price index of the Tehran Stock Exchange is positively associated with the real exchange rate. The findings also indicate that about $36 \%$ of the imbalances are modified towards the long-term modifications.

Baktash (2012) explored the effective factors for predicting the stock price index of the Tehran Stock Exchange over 1997 to 2008. Using OLS method, the collected data was analyzed. The dependent variable was the total stock price index of the Tehran Stock Exchange and the independent variables were interest rate, inflation rate, gross domestic production and interest rate. The findings showed that the interest rate, inflation rate and gross domestic production have negative impacts on the exchange rate and positive impacts on predicting the stock price index.

\section{The model and empirical results}

The most important theory about the relationship between stock price index and macro monetary variables is Fisher theory which is used as a basis for modeling the stock price index. According to Fisher, the expected interest rate should reflect the whole inflation expectations to achieve the real interest rate. The real interest rate is determined by factors such as capital productivity and time preferences of the consumers. This rate is also found to be independent of the expected inflation. Principally, Fisher theory might be generalized into each asset such as common stocks, real assets and other financial risky securities.

The main equation of Fisher states that the real interest rate is obtained from the difference between nominal interest rate and inflation rate:

$R_{t}^{r}=R^{n}{ }_{t}-I N F_{t}$, 
where $R^{r}$ - real interest rate, $R^{n}$ - nominal interest rate, INF - inflation.

Fisher describes this relationship for the stock return as follows:

$R S_{t}^{r}=R S^{n}{ }_{t}-I N F_{t}$,

where $R S^{r}$ - real interest rate, $R S^{n}$ - nominal interest rate.

The nominal return is equal to the rate of changes in the stock price:

$R S^{n}{ }_{t}=d \operatorname{Ln} P S_{t}$,

where $P S_{t}-$ stock price.

Based on this equation, Fisher introduces the econometric model and states that the inflation rate impacts the stock return:

$R S^{r}=\gamma_{0}+\gamma_{1} I N F+U_{t}$

Fama (1981) argues that some macro monetary variables (such as liquidity and interest rate) have been overlooked in the Fisher model. Fama considered the balance in the monetary market by involving the relationship between money market and stock exchange.

$\frac{M_{t}}{P_{t}}=m\left(Y_{t}, R_{t}\right)$,

where $M_{t}$ - liquidity in economy (funds on hand and long-term deposits), $P_{t}$ - public level of prices, $Y_{t}-$ national income, $R_{t}$ - interest rate.

Fama develops the following equation for the balance in the money market. This theory is then attributed to Fisher theory:

$\operatorname{Ln}\left(\frac{M_{t}}{P_{t}}\right)=\alpha_{1} \operatorname{Ln} Y_{t}-\alpha_{2} R_{t}$

$\alpha_{1}, \alpha_{2}>0$

$\operatorname{Ln} P_{t}=-\alpha_{1} \operatorname{Ln} Y_{t}+\alpha_{2} R_{t}+\operatorname{Ln} M_{t}$.

The following equation is obtained as follows:

$d \operatorname{Ln} P_{t}=-\alpha_{1} \mathrm{~d} \operatorname{Ln} Y_{t}+\alpha_{2} d R_{t}+d \operatorname{Ln} M_{t}$.

Given:

$I N F=d \operatorname{Ln} P_{t}$

$I N F_{t}=-\alpha_{1} d \operatorname{Ln} Y_{t}+\alpha_{2} d R_{t}+d \operatorname{Ln} M$.

By replacing this statement in equation (4):

$R S_{t}^{r}=\gamma-\gamma_{1} \alpha_{1} d \operatorname{Ln} Y_{t}+\gamma_{1} \alpha_{2} d R_{t}+\gamma_{1} d \operatorname{Ln} M_{t}+U_{t}$.

This relationship is restated as follows:

$R S_{t}^{r}=\beta_{0}+\beta d L n Y t_{1}+\beta_{2} d R_{t}+\beta_{3} \mathrm{~d} L n M_{t}+U_{t}$.

So that:

$\beta_{0}=\gamma_{0}, \beta_{1}=-\gamma_{1} \alpha_{1}, \beta_{2}=\gamma_{1} \alpha_{2}, \beta_{3}=\gamma_{1}$.

By using the existing relationship between nominal return and real return:

$\left(R S^{n}{ }_{t}=R S^{r}+I N F_{t}\right)$.

The above equation is written as follows:

$R S^{n}{ }_{t}=\beta_{0}+\beta_{1} L n Y t_{1}+\beta_{2} d R_{t}+\beta_{3} d L n M_{t}+\beta_{4} I N F_{t}+U_{t}$.

This equation for the stock price is written as follows:

$L n P S_{t}=\beta_{0}+\beta_{1} L n Y t_{1}+\beta_{2} R_{t}+\beta_{3} L n M_{t}+\beta_{4} P_{t}+U_{t}$. 
Equation (12) is a basic equation for describing the changes in the stock price. Given the variables of each study, other factors might be substituted by the existing variables in the equation. In this study, for example, the real interest rate is added to this formula and the national revenue and interest rate are eliminated from the formula.

\subsection{Model description}

To examine the long-term relationship of the Tehran Stock Exchange with the macro-monetary variables, the following econometric relationship is described as follows:

$P_{t}=\beta_{1} I N F_{t}+\beta_{2} M_{t}+\beta_{3} R E R_{t}+U_{t}$.

where $P_{t}$ - total stock price index of the Tehran Stock Exchange, $I N F_{t}-$ inflation, $M_{t}$ - liquidity, $R E R_{t}-$ real exchange rate.

\subsection{Econometric results}

The model of Angel-Grenjer deals with small samples and does not consider dynamic short-term reflections between the variables. The estimations made from this model are not free of bias and testing the hypotheses by using $t$-statistics does not seem valid. Consequently, those models associated with short-term dynamics and the models which lead to the estimation of more precise coefficients should not be considered. According to the empirical studies, ARDL is used to estimate the model. When the stationary of the variables are at the same level, we are not allowed to use $t$-statistics developed by Banerji, Dolado and Master. Based on ADF test, inflation and other variables are station at zero $\left(I_{(0)}\right)$ and one $\left(I_{(1)}\right)$ levels, respectively. Using Microfit5, ARDL $(1,0,0,0)$ model is selected based on Schwartz-Basin measure and the estimated result for the short-term is shown in the following Table:

Table 1. Model ARDL for stock price index

\begin{tabular}{|c|c|c|c|}
\hline Variable & Coefficient & Std. deviation & $0 / 000$ \\
\hline$S P I(-1)$ & $0 / 92422$ & $0 / 031378$ & $0 / 001$ \\
\hline$I N F$ & $-0 / 0037382$ & $0 / 0010758$ & $0 / 017$ \\
\hline$M$ & $0 / 00000050$ & $0 / 00000020$ & $0 / 065$ \\
\hline$R E R$ & $-0 / 0007275$ & $0 / 0003889$ & $0 / 004$ \\
\hline Intercept & $0 / 70479$ & $0 / 24004$ & $D W=1 / 31$ \\
\hline$R^{2}=0 / 98$ & \multicolumn{2}{|c|}{$F(78.4)=1319 / 5(0 / 000)$} \\
\hline
\end{tabular}

Before estimating the long-term coefficients based on ARDL, a long-term co-integrated relationship should be confirmed. Since, the stationary levels of the variables are not similar; $t$-statistics (developed by Banerjee, Dolado and Mestre (1992)) should be used to examine the co-integration between these variables. The null hypothesis confirms the non-accumulation or long-term relationship. The condition for moving the dynamic short-term relationship to the long-term balance is that the sum of the coefficients of the explanatory variables should be lower than one. Based on Schwartz-Basin measure, the number of the optimum disturbance in the dependent variable is equal to one; therefore, the null hypothesis about the model of stock price index becomes as follows:

$$
H_{1}: \alpha_{i}-1 \leq 0 \& H_{0}: \alpha_{i}-1 \geq 0 \text {. }
$$

The quantity of t-statistics for estimating the successful test is calculated so that one is deducted from the sum of the coefficients with disturbances of the dependent variable and is then divided by the total standard deviation of the coefficients. If the absolute value of the calculated $t$ is greater than the absolute value of the critical values provided by Banerjee, Dolado and Mestre (1993), the null hypothesis is rejected and a longterm relationship is confirmed. Otherwise, the first hypothesis is confirmed (Tashkini, 2005).

$$
\frac{\sum_{i=1}^{p} \hat{\alpha}_{i}-1}{\sum_{i=1}^{p} S \hat{\alpha}_{i}}=\frac{\hat{\alpha}_{i}-1}{S \hat{\alpha}}=\frac{0.92422-1}{0.031378}=-2 / 41 .
$$


The above quantity in this model is -2.41 ; therefore, $\mathrm{H} 0$ is rejected at the 98 percent level of significance. It can be then concluded that there is a long-term relationship between the model variables. The following table shows the long-term relationship.

Table 2. Estimating the long-term coefficients of the stock price index

\begin{tabular}{|c|c|c|}
\hline Variable & Coefficient & Sig. \\
\hline$I N F$ & $-0 / 0493$ & $0 / 040$ \\
\hline$M$ & $0 / 0000067$ & $0 / 000$ \\
\hline$R E R$ & $-0 / 000967$ & $0 / 072$ \\
\hline Intercept & $9 / 8370$ & $0 / 000$ \\
\hline
\end{tabular}

As shown from the significant coefficients of the above Table, the real exchange rate is significant at the 90 percent level and the two other variables are found to be significant at $95 \%$.

\subsection{Error Correction Model (ECM)}

The short-term model of error correction is a feedback mechanism based on which the dependent variable (stock price index) is modified in relation to the imbalances created in the short-term. In fact, the stated mechanism guarantees the achievement of the long-term balance. To determine the speed at which the shortterm imbalances are modified towards the long-term, ECM model is used. What seems important in ECM model is the negative coefficient of EC which indicates the modification speed of the imbalance towards the long-term.

Table 3. ECM model for the stock price index

\begin{tabular}{|c|c|c|}
\hline Variable & Coefficient & Sig. \\
\hline$d I N F$ & $-0 / 0037$ & $0 / 001$ \\
\hline$d M$ & $0 / 0000005$ & $0 / 017$ \\
\hline$d R E R$ & $-0 / 000086$ & $0 / 061$ \\
\hline$C$ & $0 / 704$ & $0 / 004$ \\
\hline$E C(-1)$ & $-0 / 075$ & $0 / 018$ \\
\hline$R^{2}=0 / 67$ & $F(78.4)=6 / 94(0 / 000)$ & $D W=1 / 31$ \\
\hline
\end{tabular}

As shown in Table above, the balancing speed of the imbalance process or EC coefficient is -0.075 and shows that 0.075 of the imbalances of the stock price index are removed.

\subsection{Analysis of the results}

In analyzing the model estimation, the following conclusions are provided:

1. In the long-term, the stock price index is negatively associated with the inflation. By increasing inflation, the current costs of the individuals increase and the purchase power of the people decrease. This, in turn, causes the revenues to be spent over the current costs. The increase in the costs results in revising the assets basket of the individuals to maintain the value of their assets. In the inflation period, however, the nominal earnings increase without a real increase in the profitability. Therefore, the quality of the real earnings decreases and the intrinsic value of each stock decreases. This factor results in a decrease in the investment of the capital market and this is consistent with the theoretical bases of the study.

2. Based on the findings, the liquidity is found to have a positive relationship with the stock price index. In terms of the positive relationship between the stock price index and liquidity, it can be concluded that the money effectiveness is significant from two aspects. The first aspect is that it is a macroeconomic variable; the second aspect concerns with the fact that these variables are considered in the investment portfolio in the financial market.

By increasing liquidity, the demand for investment and especially for the stocks increases. As a result of increasing demand for the stocks, the stock price and the total stock price index increase. By increasing liquidity and its attraction by the stock exchange and using this liquidity in real production, the productions and the stock value increase. Attracting liquidity by the stock exchange and using it in the production might prevent the increase in inflation in the long-term. This is consistent with the theoretical bases of the study. 
3. In analyzing the reverse relationship between the exchange rate and stock price index, it can be concluded that many economic participants need to import the raw materials, machinery and technology from the other countries. They are confronted with exchange demand and the changes in the exchange rate will not impact the manufacturing trend of the companies. For example, increasing the exchange rate causes an increase in working capital to maintain the current production level. In doing so, the interest rate increases as the result of increases in the price of the materials and other requirements. This would be accompanied by a decrease in earnings and also stock price which would reduce the stock price index. Based on the conclusions in the short-term and long-term, this effect is negative. The main reason for this negative impact is that the country is developing and its manufacturing departments are tied to import.

\section{Conclusion}

The stock exchanges constitute the main parts of the capital market and play the role of attracting and directing the savings and liquidity to finance the manufacturing enterprises. The present study seeks to examine the way the stock price index and Tehran Stock Exchange are affected by the macroeconomic variables such as inflation, liquidity and real exchange rate. Using ARDL, the risks from the external factors in the capital market are examined. The findings revealed that inflation and real exchange rate have negative impacts in the long-term; however, the liquidity has positive effects on the stock price index. Based on ECM model, it was found that the modifying speed of the short-term imbalances towards long-term have negative signs equal to 0.075 . As a result, the stock price index is moving to a balance by macroeconomic variables. Introducing the external factors causing risks in the capital market, identifying the way these factors impact the investments and planning for reducing the risks from these factors are among the requirements of the capital markets of the developing countries.

\section{References}

1. Ebrahimi, M.; Shekari, N. (2011). The impact of macroeconomic variables on the stock price by emphasizing on the role of the monetary policy. Economic Modeling Quarterly, Fifth Year, No. 1.

2. Central Bank of Islamic Republic of Iran, Researches of the economic studies over different years.

3. Baktash, L. (2012). The effective factors of predicting stock price index of the Tehran Stock Exchange over 1997 to 2008. The first international conference on econometric and its applications, Islamic Azad University of Sanandaj.

4. Empirical analysis of inflation and monetary policy rule in Iran (2006). Central Bank of Islamic Republic of Iran.

5. Saeidi, P., Amiri, A. (2008). The relationship between inflation and stock price of the industries in the Tehran Stock Exchange. Managerial Quarterly, No. 12.

6. Taheri, H., Sarem, M. (2011). The relationship between the exchange rate and the stock price index of the Tehran Stock Exchange by using ARDL. Economic Studies Quarterly, 60, 63-80.

7. Karim Zadeh, M. (2006). Examining the long-term relationship between stock price index and macromonetary variables in Iran's economy. Economic Researches of Iran, No. 26.

8. Karim Zadeh, M., Soltani, A. (2010). Estimating the long-term relationship of the stock price index of the financial intermediaries with the macro-monetary variables by using ARDL. Financial Accounting Quarterly, 6, 1-18.

9. Mousayi, M., Mehrgan, N. and Amiri, H. (2010). The relationship of the stock market and macroeconomic variables in Iran. Economic Studies and Policies, 54, 73-94.

10. Yari, S., Farmandoust, K. (2012). The main factors of determining the stock price. Stock Exchange Journal, No. 33.

11. Alam, Mahmudul, and Salah Uddin, G. (2009). Relationship between Interest Rate and Stock Price: Empirical Evidence From Developed and Developing Countries. International Journal of Business and Management, 4(3).

12. Asaolu, T.O., and Ogunmuyiwa M.S. (2011). An Econometric Analysis of the Impact of Macroecomomic Variables on Stock Market Movement in Nigeria. Asian Journal of Business Management, 3(1), 72-78.

13. Bhattacharyya, B. and Mukherjee, J. (2006). Indian Stock Price Movement and the Macroeconomic Context : A Time Series Analysis. Journal of International Business and Economics, 5(1), 167-181.

14. Fama, E.F. et al. (1977). Assets Returnes and Inflation. Journal of Financial Economics, 5, 115-146. 
15. Ibrahim, M.H. (1999). Macroeconomic Variables and Stock Prices in Malaysia: an Empirical Analysis. Asian Economic Journal, 13, 219-231.

16. Imran \& et al. (2010). Causal Relationship between Macroeconomic Indicators and Stock Exchange Prices in Pakistan. African Journal of Business Management, 4(3).

17. Ioanidis, Ch. and A. Kontonikas. (2007). the Impact of Monetary Policy on Stock Prices. Journal of Policy Modeling, 6(15).

18. Mookerjee, R. and Yu, Q. (1997). Macroeconomic Variables and Stock Prices in Small Open Economy: The Case of Singapore. Pacific-Basin Finance Journal, No. 5.

19. Naik Kumar, P. and Padhi, P. (2012). the Impact of Macroeconomics Fundamentals on Stock Price Revisited: Evidence from India Data. Eurasian Journal of Business and Economics, 5(10), 25-44.

20. Zubeiru, Salifu, Kofi, A. and Charles, K.D. (2007). Foreign Exchange Risk: Exposure of Listed Companies in Ghana. The Journal of Risk Finance, 8(4), 380-393. 